\title{
Using downside CAPM theory to improve customer lifetime value prediction in non-contractual setting
}

\author{
Amir Albadvi ${ }^{a^{*}}$ and Ashraf Norouzi ${ }^{b}$
}

${ }^{a}$ Professor of Industrial Engineering, Faculty of Engineering, Tarbiat Modares University, Tehran, Iran ${ }^{b}$ PhD student in Industrial Engineering, Faculty of Engineering, Tarbiat Modares University, Tehran, Iran

\section{CH R O N I C L E}

\section{Article history:}

Received May 12, 2013

Received in revised format

12 September 2013

Accepted 7 October 2013

Available online

October 222013

Keywords:

Customer lifetime Value (CLV)

Capital Asset Pricing Model

(CAPM)

Downside beta

Marketing finance interface

\section{A B S T R A C T}

Identifying and selecting the most profitable customers from a shareholder's perspective is of great interest to marketing managers. One promising line in this regard is to explore the customer lifetime value and its profitable management over time. There is a significant body of marketing literature about CLV evaluation in terms of various perspectives. However, much less attention has been paid to the risk associated with customer relationships. Previous researches in this area considered risk as "variability of cash flows generated by customers", regardless of the trend of variability. Whereas the upside and downside variability from the customer's expected profitability are extremely different in CRM context. This paper provides a quantitative model based on downside Capital Asset Pricing Model (D-CAPM) to evaluate riskadjusted CLV and compares the results by employment of traditional CAPM. This paper contributes to this field by extending the discussion on customer risk measurement and provides an approach that enables marketing managers to evaluate the risk of decline from average profitability for different customer segments.

\section{Introduction}

Managing organizational assets in a way that maximizes a company's shareholder value is the main goal of every organization (Srivastava et al., 1998). To achieve this goal and to create shareholder value, every investment, under a certain level of risk, must return more than the firm's cost of capital. The cost of capital reflects the minimum expected return by company's shareholders. While considering these concepts in managing tangible assets is crucial for financial managers, much less attention has been devoted on managing intangible assets. (Rego et al., 2009; Tarasi, et al. 2011). Among different Intangible assets, customer relationships is the most valuable one (Gruca \& Rego 2005; Gupta et al., 2004; Hogan, et al. 2002; Ryals, 2003). There are various metrics to evaluate customer relationships. Among them, Customer Lifetime Value (CLV) is the most popular measure for evaluating customer relationship assets and a great effort has been made for its determination and

*Corresponding author. Tel: +98 2182883395

E-mail address: albadvi@modares.ac.ir (A. Albadvi) 
prediction both in theory and practice (e.g., Berger \& Nasr, 1998; Dwyer, 1997; Gupta et al., 2004; Jain \& Singh, 2002; Reinartz \& Kumar 2000; Rust et al., 2004). CLV concept is borrowed from financial asset valuation models (i.e. discounted cash flow model) and is defined as discounted cash flow generated from the customer through her lifecycle horizon (Berger \& Nasr, 1998; Dwyer, 1997; Jain \& Singh 2002):

$\operatorname{CLV}_{\mathrm{i}}=\sum_{t=1}^{T} \frac{\text { Profit }_{\mathrm{i}, \mathrm{t}}}{(1+\mathrm{d})^{\mathrm{t}}} \mathrm{i}=1, \ldots, \mathrm{N}$

where Profit $t_{i, t}$ is the net cash flow generated from customer $i$ in period $t, t=1, \ldots, T$ is the time period, $N$ is the number of customers and $d$ is the discount rate.

If future cash flows generated by a customer (profit in future periods) were known with certainty, the financial value of relations would be estimated simply by calculating the net present value of customer's cash flow over lifetime period. In a similar way, the value of whole customer base would be the aggregation of the net cash flows generated by its customers. In the real world, however, the future cash flows generated by customers are uncertain. The uncertainty associated with cash flow is defined as the difference between expected returns and the actual amounts, which are realized. This uncertainty is characterized as "risk". Despite the fact that CLV based models are generally formed from financial valuation viewpoint, the aspect of risk, which is central to financial valuation models, has been widely neglected here (Wangenheim \& Lentz, 2005; Ryals \& Knox, 2005; Sackmann et al., 2010; Stahl et al., 2003; Kundisch et al., 2008; Tarasi, et al. 2011). The aspect of risk is usually incorporated in CLV models by means of risk-adjusted discount rate. In this approach, a customer with less stability of cash flow evaluated less than one with more stable cash flow. There are few researches about stability of cash flows generated by customers and how it varies over time (Gruca \& Rego, 2005). We know that loyalty of customers is generally growing over time (Reichheld, 1996) and more loyal customers generate more stable and growing cash flows (Gruca \& Rego, 2005). However, there is no clear approach to take into account the growing/declining trends in common CLV evaluation models (i.e. in a way that growing cash flow being evaluated more than declining one). In this research, we propose a new approach to focus on downside cash flow variability as customer relationship risk. The proposed approach offers a systematic way to take into account the risk associated with customer value decline in customer CLV modeling.

The paper is organized as follows: The next section gives a review on research background about incorporation of Capital Asset Pricing Model (CAPM) in CRM applications. Section 3 introduces the research design and the phases of empirical research practice. This section also provides descriptions about Pareto/NBD modeling used to examine CLV in empirical phases of this research. In Section 4, our risk-adjusted CLV evaluation model is introduced and applied via three phases. In the first phase, the customer base is clustered into homogenous segments using RFM segmentation technique. In the second phase the risk associated with every customer segment as cash flow volatility generated by that segment, is estimated. This estimation is carried out using two approaches: standard CAPM model and so-called D-CAPM model which measures risk from downside perspective. Subsequently in phase 3 the well-known Pareto/NBD model is applied to examine CLV of customer base. Different values of risk-adjusted discount rates provided by the previous phase are being used in application of this model.

\section{Research Background}

Different researches in CRM literature have proposed and used Capital Asset Pricing Model to incorporate customer risk in CLV models. (Buhl \& Heinrich, 2008; Dhar \& Glazer 2003; Gupta et al., 2004; Hogan et al., 2002; Hopkinson \& Lum, 2002; Ryals, 2003; Tarasi et al., 2011; Wangenheim \& 
Lentz, 2005). The CAPM model is based on the assumption that investors are rational and risk averse. (i.e. they ask for more reward when bearing higher risk). The total risk associated with an asset is formed from two parts: systematic and non-systematic risk. The systematic part is associated with the whole market and therefore influences all assets, but the unsystematic part is associated with a specific asset. CAPM states that the non-systematic risk can be decreased by the idea of diversification, whereas the systematic risk cannot. Therefore, investors need to have reward to accept this kind of risk. This risk is measured via covariance of any asset's cash flow with market. The reward to risk ratio in this model is:

$\frac{E\left(R_{i}\right)-R_{f}}{\beta_{i}}=E\left(R_{m}\right)-R_{f}$

where $\mathrm{E}\left(\mathrm{R}_{\mathrm{i}}\right)$ is the expected return of asset $i, \mathrm{E}\left(\mathrm{R}_{\mathrm{m}}\right)$ is the expected return of market (or any reference asset), $R_{f}$ is the return of risk free asset and $\beta_{\mathrm{i}}$ is the excess expected asset return to the expected excess market return.

$\beta_{i}=\frac{\operatorname{Cov}\left(R_{i}, R_{m}\right)}{\operatorname{Var}\left(R_{m}\right)}$

Dhar and Glazer (2003) are believed to be the first who introduced this idea into CRM literature where the customer base is being assumed as market and every customer segment as an investment asset in market. The customer beta ratio captures the degree in which an individual segment contributes to the risk of entire customer base. In this context there is no risk free asset (a customer with certain future cash flow). So this quantity is assumed to be zero. In line with Tarasi et al. (2011) we define $R_{i}$ as the cash flow generated by segment $i$ and $R_{m}$ as the total cash flow generated by entire customer base. Then in CLV model, the discount rate of any customer segment is multiplied by its corresponding beta to provide risk-adjusted CLV evaluation.

The main advantage of CAPM model is to consider interdependencies between the assets risk structure and their effect on each other as a whole portfolio. However, this model has been criticized from different aspects in financial literature. These criticisms are mainly about its restrictive assumptions such as use of normal distribution to model return streams, assuming that correlations between assets are fixed and constant and considering both upside and downside risk as equally undesirable. The uncertainty associated with returns could be classified as upside and downside risk. Downside risk is the risk associated with losses. That is, the risk that actual return is less than the expected return. In contrast, the upside risk is the risk in which actual return is more than expected value. Because of these shortcomings, some extensions from CAPM model have been developed. One of them is downside CAPM introduced by Estrada (2002). D-CAPM overcomes the gaps of traditional CAPM especially in the cases that return streams have asymmetric nature. This model uses downside semi variance instead of variance to capture asset's risk. Estrada defined downside beta of asset $i$, where we denote by $\beta_{i}^{D}$ as follows,

$\beta_{i}^{D}=\frac{\text { downside covariance }_{i, M}}{{\text { downside } \text { variance }_{M}}_{\text {awin }}}=\frac{\operatorname{cov}\left(R_{i}, R_{M} \mid R_{M}<\mu_{M}\right)}{\operatorname{var}\left(R_{M} \mid R_{M}<\mu_{M}\right)}=\frac{E\left\{\operatorname{Min}\left[\left(R_{i}-\mu_{i}\right), 0\right] * \operatorname{Min}\left[\left(R_{M}-\mu_{M}\right), 0\right]\right\}}{E\left\{\operatorname{Min}\left[\left(R_{M}-\mu_{M}\right), 0\right]^{2}\right\}}$

where $R_{i}$ is the return stream of asset $i, R_{M}$ is the return stream of market, and $\mu_{i}$ and $\mu_{M}$ are their average values respectively.

In customer lifetime value evaluation, there is an obvious distinction between the two directions of variability (i.e. customer growth or decline in relations). This pinpoints that studying variability of cash flows regardless of their direction of movement is insufficient for CLV prediction. Without attention to the direction of volatility, CLV model will under-valuate both customers who are 
growing and declining from their average cohort value. Therefore, using a downside-risk measure could be an appropriate choice in this case.

\section{Research Design}

This study was carried out on customer relationships at an Iranian financial service firm. Customer relationships in this case have a non-contractual setting. The raw data provided for this study was 32 months transactional dataset (from 01/04/2009 to 30/11/2011). This dataset was composed of three data fields containing Customer ID, Date of Transaction and monetary value of every transaction from 3632 customers. The dataset was divided into two equal time intervals. The first 16 months was considered as train set and the next 16 months as test set. Test data was only used to evaluate the results and was not used at any other stages of research.

As stated earlier, this study was conducted in three phases. In the first phase using RFM model, the customers were classified into eight segments. In the second phase, the average monetary cash flow from every customer segment was calculated. These cash flows were being compared with monthly cash flow generated by an average customer as a benchmark. Then using CAPM model the values of beta and downside beta associated with every customer segment were estimated and the risk-adjusted discount rates according to them were calculated. In the third phase, we used Pareto/NBD modeling to estimate the CLV associated with every customer segment. This estimation was fulfilled using different discount rates provided by traditional and downside CAPM in the previous step. The real value realized by different customer segments across the test period, was used to compare the employment of these two risk-adjustment techniques in CLV evaluation. All computational work of this paper is carried out using MATLAB software.

The empirical steps of this study and the models employed in every step are illustrated in Fig.1.

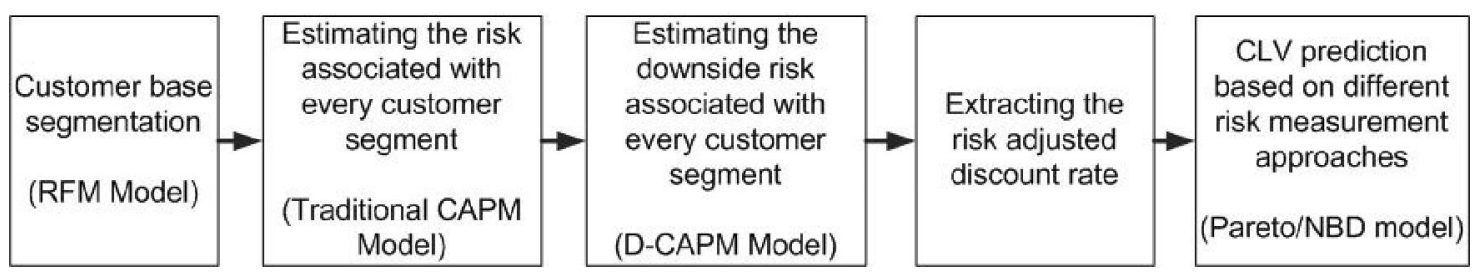

Fig. 1. empirical phases of risk-adjusted CLV evaluation model

CAPM model and its extension developed by Estrada (2002) were introduced in the previous section. The following provides a brief description about Pareto/NBD model where we used in the last phase of the research.

\subsection{Pareto/NBD Model}

Pareto/NBD which introduced by Schmittlein et al. (1987) is a probability approach to model CLV. Probability models assume that customers' behavior varies across the population according to specific distribution. Pareto/NBD model is a powerful tool to describe customer behavior in noncontractual setting and therefore it was used to estimate customers' CLV in this research.

This model makes some assumptions about customer buying behavior (Fader, et al. 2005):

1. Customer relationships with a firm consist of two phases. In the first phase, she is active across an "unobserved" time period and then in the second phase she becomes inactive permanently.

2. When the customer is still active, the number of transactions follows a Poisson distribution.

3. Heterogeneity in the number of transactions follows a gamma distribution across population. 
4. Customer's lifetime duration has exponential distribution.

5. Heterogeneity in the customer's dropout rates follows gamma distribution.

6. Transaction and dropout rates vary independently from each other.

The second and the third assumptions yield NBD distribution while the next following two assumptions result the Pareto of the second kind distribution. This model uses three pieces of information about customers' past behavior: "recency" when the last transaction occurred, "frequency" how many transactions were occurred and the time period within which the customer behavior was observed. The notation $\left(x_{i}, t_{i}, T_{i}\right)$ represents these parameters respectively where $x_{i}$ is the number of transactions made by customer $i$ in the time period $\left(0, T_{i}\right]$ and $t_{i}\left(0<t_{i} \leq T_{i}\right)$ is the time of customer's last transaction. Using these data fields, Schmittlein, et al. (1987) derived some interesting quantities to describe customer's future behavior where $\left(P_{\text {alive }} \mid x_{i}, t_{i}, T_{i}\right)$ is the probability that a customer with behavior and $\left(x_{i}, t_{i}, T_{i}\right)$ is alive at time $\mathrm{T}$ and $E\left[Y(t) \mid x_{i}, t_{i}, T_{i}\right]$ is the expected number of transactions in time period $\left(T_{i}, T_{i}+t\right]$.

Some extensions from this basic model have been developed to make it possible to calculate CLV directly from Pareto/NBD modeling. To achieve this goal it is necessary to model the monetary value of customer cash flow. Fader et al (2004) make some assumptions in this regard:

- The monetary values generated by a customer vary independently from her number of transactions.

- The monetary values follow a gamma distribution

- Heterogeneity in monetary values has a gamma distribution across customers.

- Mean monetary values differ among customers but do not vary over time for any given customer.

Fader et al. (2004) derived the following explicit formula to estimate the expected CLV for a customer:

$$
C L V\left(\delta \mid r, \alpha, s, \beta, p, q, \gamma, x, t_{x}, T\right)=\frac{\alpha^{r} \beta^{s} \delta^{s-1} \Gamma(r+x+1) \Psi(s, s ; \delta(\beta+T))}{\Gamma(r)(\alpha+T)^{r+x+1} L\left(r, \alpha, s, \beta \mid x, t_{x}, T\right)} \times \frac{\left(\gamma+m_{x} x\right) p}{p x+q-1}
$$

where $(r, \alpha, s, \beta)$ represent the parameters of Pareto/NBD model and $(\mathrm{p}, \mathrm{q}, \gamma)$ are the parameters of transactional value model, $\Psi$ is the confluent hypergeometric function of the second type and $L$ is the Pareto/NBD likelihood function. These parameters could be estimated via Maximum Likelihood Estimation (MLE) approach. For more details about Pareto/NBD and transactional value likelihood functions, see Schmittlein and Peterson (1994) and Fader et al. (2004) for details.

\section{Experimental Results}

This section describes the empirical results of the research through three main phases.

\section{Phase1: Customer Segmentation according to Their Relationship Strength}

The RFM model is a common and well-known method of customer value analysis. This model, which is introduced by Hughes (1994) analyzes the behavior of customers over time. Because of considering customer behavior, it is a well-known method to measure the strength of customer relationship especially in the case of non-contractual setting and therefore is used here. Using this approach, customers are clustered by three attributes: recency (the time interval from the customer's last purchase until now), frequency (number of transactions in a particular period) and monetary (amount of money in a particular period). We calculated the recency as the number of months elapsed from the customer's last purchase; frequency as the number of customer transactions and the monetary value as the average amount of money spent by a customer per an active period. We prefer the use of 
average monetary value to its total accumulated amount in order to reduce the synergistic effect of frequency and monetary on each other. In addition, in this case, because of the non-contractual setting of relationships, the average per active periods is preferred to the average over entire lifetime. Then, every RFM attribute was partitioned into two classes: more than and below its average value. Therefore, the customer base was segmented into eight classes of customers. Table1 provides some details about different customer segments and their average RFM values.

Table 1

Customer segmentation based on RFM variables

\begin{tabular}{llllll}
\hline Segment & $\begin{array}{l}\text { Segment } \\
\text { Description }\end{array}$ & $\begin{array}{l}\text { No of } \\
\text { Customers }\end{array}$ & $\begin{array}{l}\text { Average Recency } \\
\text { (Months) }\end{array}$ & $\begin{array}{l}\text { Average } \\
\text { Frequency }\end{array}$ & $\begin{array}{l}\text { Average Monetary } \\
\text { (in 100,000 rials) }\end{array}$ \\
\hline 1 & $\mathrm{R} \downarrow \mathrm{F} \uparrow \mathrm{M} \uparrow$ & 89 & 1.2446 & 11.5843 & 4.1794 \\
2 & $\mathrm{R} \uparrow \mathrm{F} \uparrow \mathrm{M} \uparrow$ & 19 & 8.8333 & 5.011 & 4.6231 \\
3 & $\mathrm{R} \downarrow \mathrm{F} \downarrow \mathrm{M} \uparrow$ & 131 & 2.1583 & 1.29 & 7.6789 \\
4 & $\mathrm{R} \downarrow \mathrm{F} \uparrow \mathrm{M} \downarrow$ & 132 & 2.0010 & 7.8864 & 1.9096 \\
5 & $\mathrm{R} \uparrow \mathrm{F} \downarrow \mathrm{M} \uparrow$ & 175 & 9.1798 & 1.1143 & 10.8126 \\
6 & $\mathrm{R} \uparrow \mathrm{F} \uparrow \mathrm{M} \downarrow$ & 88 & 10.6750 & 8.375 & 1.4885 \\
7 & $\mathrm{R} \downarrow \mathrm{F} \downarrow \mathrm{M} \downarrow$ & 455 & 3.7001 & 1.2439 & 2.6534 \\
8 & $\mathrm{R} \uparrow \mathrm{F} \downarrow \mathrm{M} \downarrow$ & 417 & 10.2676 & 1.1312 & 2.5869 \\
\hline Total & & 1506 & 6.1995 & 2.9933 & 3.0729 \\
\hline
\end{tabular}

Phase 2: Estimating beta and downside beta values across different customer segments

Our examination is based on the monthly profit realized by different customer segments. Fig. 2 provides a graph of average monthly profit generated by a customer from different segments. This value is yielded from monthly profit generated by a segment divided by its number of active members within every time period. As it is indicated in Figure 2 there are various trends of profitability among different segments. For example, segments1 and 4 exhibit a clear growth while the others have relatively low growth or decline in profitability over time.

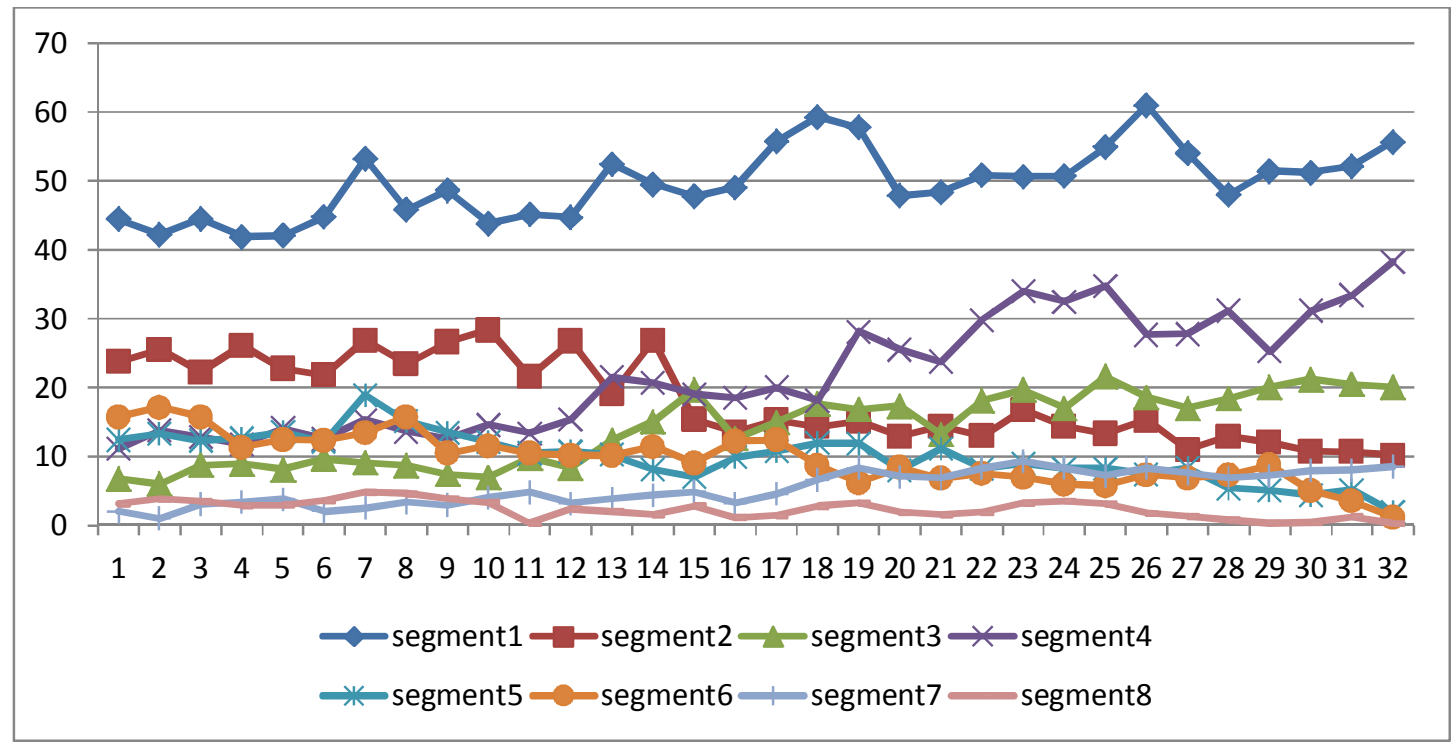

Fig. 2. Monthly Average Profit Generated by an average active Customer from different Segments (in 100,000 rials)

In order to calculate the riskiness of every customer segment, we used the CAPM theory. We define the beta coefficient for every customer segment. Considering average cash flow per active customers for segment $\mathrm{i}$ as $R_{i}$ and the average cash flow per active customers for entire customer base as the benchmark $R_{m}$, the $\beta_{i}$ is yielded from Eq. (3). Similarly the downside beta for every customer 
segment could be estimated from Eq. (4). Table 2 summarizes the results for different customer segments.

Table 2

Standard beta Versus Downside beta for different Customer Segments

\begin{tabular}{ccc}
\hline Segment & Down side beta & Standard beta \\
\hline Segment1 & 2.679944 & 2.857899 \\
Segment2 & 1.100949 & -0.92919 \\
Segment3 & 3.712095 & 3.278186 \\
Segment4 & 2.013216 & 2.070748 \\
Segment5 & 3.948611 & 2.229359 \\
Segment6 & 1.230111 & 0.227577 \\
Segment7 & 0.333279 & 0.277915 \\
Segment8 & 0.212951 & 0.071714 \\
\hline
\end{tabular}

We compute the variance of entire customer base using the formula $\operatorname{Var}_{M}=\frac{\sum_{M=1}^{N}\left(R_{M}-\mu_{M}\right)^{2}}{N-1}$ where $R_{M}$ is the cash flow generated from all active customers in time period $M, N$ is the number of time periods considered, and $\mu_{M}$ is the average value of entire customer portfolio over $N$ periods. Tables 2 and Table 3 summarize the results of estimations about covariance and beta values in standard and downside forms respectively.

Table 3

Standard Covariance versus Downside Covariance between Customer Segments and Average portfolio

\begin{tabular}{ccc}
\hline Segment & $\begin{array}{c}\text { Downside Covariance between } \\
\text { segments and Average portfolio }\end{array}$ & $\begin{array}{c}\text { Standard Covariance between segments and } \\
\text { Average portfolio }\end{array}$ \\
\hline segment1 & 2.1139 & 3.6561 \\
segment2 & 0.8684 & -1.1887 \\
segment3 & 2.9280 & 4.1938 \\
segment4 & 1.5879 & 2.64913 \\
segment5 & 3.1145 & 2.8520 \\
segment6 & 0.9703 & 0.2911 \\
segment7 & 0.2629 & 0.3555 \\
segment8 & 0.1679 & 0.0917 \\
\hline
\end{tabular}

The variance of portfolio is $\operatorname{Var}\left(R_{m}\right)=1.2793$ and the downside semi variance ${ }_{M}=0.7888$, which exhibits the non-symmetric distribution of values generated by customer segments about the mean. The downside variance is less than the standard variance. Therefore, because of the positive skewness of distribution, the downside risk assessment approach evaluates cash flows more than the standard approach.

The CAPM theory captures every asset's degree of risk by means of beta coefficient. This value is multiplied by discount rate to provide risk-adjusted discount rate. So the customer with more volatility in returns against average (or any given benchmark), is evaluated less than average customer base. Because of using the monthly basis in all computational steps, the discount rate should also be considered on this basis. Assuming annual discount rate as $(100 \times d) \%$ yields the monthly discount rate as $\delta=(\mathrm{d} / 12) \%$. We considered the annual interest rate of long term investment deposit in Iranian governmental banks which is $20 \%$ per year, as the minimum acceptable rate of return. Therefore the annual discount rate was assumed $20 \%$ and the monthly rate set to $\delta=$ $1.6667 \%$. This basic rate was adjusted by the factor of risk of different segments. The result is shown in Table 4. 
Table 4

Risk-Adjusted discount rate for different customer segments via different approaches of risk measurement

\begin{tabular}{lcc}
\hline Segment & Risk-adjusted discount rate & \\
\hline segment1 & Downside Semi-Variance approach & Variance approach \\
\hline segment2 & 0.0448 & 0.0477 \\
segment3 & 0.0184 & 0.0155 \\
segment4 & 0.0620 & 0.0547 \\
segment5 & 0.0336 & 0.0346 \\
segment6 & 0.0659 & 0.0372 \\
segment7 & 0.0205 & 0.0038 \\
segment8 & 0.0056 & 0.0046 \\
\hline
\end{tabular}

\section{Phase 3: Extended Pareto/NBD prediction Model based on D-CAPM and its comparison with traditional CAPM model}

As discussed earlier, we used the Pareto/NBD model to estimate lifetime value of customer base. The parameters of this model are estimated using MLE approach (see Schmittlein \& Peterson (1994) and Fader et al. (2005) for details). To fulfill this task, a dataset containing customer ID, $x_{i}, t_{i}, T_{i}$ and average monetary value $m_{i}$ was derived from primary transactional dataset. Then the likelihood functions of Pareto/NBD and transactional value model were calculated and minimized to estimate the unknown parameters of model across customers. The parameters estimate of the Pareto/NBD model are $\hat{r}=0.8573, \hat{\alpha}=1.3017, \hat{s}=0.4180, \hat{\beta}=1.7332$ and for the transactional value model $\hat{p}=3.0009, \hat{q}=6.2417$ and $\hat{\gamma}=7.5423$.

Now using Eq. (5) the lifetime value of customer with behavior $x_{i}, t_{i}, T_{i}$ and $m_{i}$ could be estimated. The Pareto/NBD model was used to estimate the CLV according to every customer segment. According to Table4 we used different discount rates for different customer segments. This estimation was conducted using both standard and downside CAPM approaches. We used the first 16 months as train set and the next 16 months as test set to estimate the predictive power of model. Using Table 4, we used different discount rates for different customer segments according to their degree of riskiness. The real value created by every customer segment along test period was considered as lifetime value realized by that segment and the prediction from Pareto/NBD model was compared to this value.

To measure prediction accuracy, we used Root of Mean Square Error (RMSE) between the prediction of CLV and its actual value. We used a trimming of $15 \%$ to improve the robustness of model against outliers. It means eliminating $15 \%$ of the largest errors from calculations. So the RMSE could be defined as:

$$
R M S E=\sqrt{\frac{1}{0.85 \times n} \sum_{i \in B P}\left(\widehat{C L V}_{i}-C L V_{i}\right)^{2}}
$$

where $\widehat{C L V}_{i}$ is the predicted value of CLV for segment $\mathrm{i}$ and $C L V_{i}$ is its realized value, $\mathrm{n}$ is the number of customers and BP is the set of $85 \%$ best predictions. The RMSE value is calculated for every customer segment as well as the entire customer base. Table 5 summarizes the results.

\section{Conclusion}

There is a considerable body of marketing literature dealing with customer relationship evaluation as an intangible asset. Although customer lifetime value evaluation methods are borrowed from financial valuation viewpoint, the aspect of risk, which is central to financial applications, is widely neglected here. The objective of this study is to provide some implications in this regard and give a detailed discussion on application of a downside risk measure in CLV context. Previous researches in 
this area used no other approach than variance of cash flows used in traditional CAPM theory to estimate customer risk. This paper extends the aspect of risk measurement in CLV context and provides some implications about applicability of downside risk measurement in this context, which have not been addressed before. Also this paper enhanced the use of D-CAPM theory for riskadjusted CLV evaluation in practice and compared its application with traditional CAPM theory.

By discussing the weaknesses of variance as classic risk measure in CLV applications, we propose to apply downside semi-variance as an alternative in this regard. This downside risk measure does not need to make restrictive assumptions such as assuming that returns distribution function is symmetric around the mean. Using downside risk and D-CAPM theory makes it possible to overcome the drawbacks associated with the use of traditional CAPM especially in the cases with asymmetric nature of returns (Estrada, 2002). As it was stated in the previous section, there is a significant difference between downside and standard variance of cash flows for different customer segments which implies the skewness of cash flow distribution function. Therefore using D-CAPM could be an appropriate choice in this case. Experimental results support this idea. The proposed risk measurement approach is applied in the case of Iranian financial service firm. As can be seen in Table 5, using D-CAPM approach improves the prediction power of model for all segments except segments 3 and 7. It also improves the total accuracy of results. In addition, implementing such an approach could be easily carried out by marketing managers. The periodic cash flows generated by customer segments are accessible data which could be easily derived from customer transactional databases.

Despite the discussed advantages of our downside risk adjusted CLV approach, this study presents some drawbacks which could be investigated by further researches. First, using D-CAPM model could only overcome some drawbacks of CAPM theory such as normality of returns or assuming upside and downside risks as equal. But some other drawbacks such as assuming underlying risk structure as fixed and constant over time are still remained. These drawbacks could stimulate further researches in this regard. Second, we used RFM segmentation approach to segment customers. Using other potential measures such as customer present and potential value, customer loyalty or demographic/firmographic attributes of customers could be potentially useful metrics in this regard.

Table 5

RMSE for CLV prediction by Pareto/NBD model and via different approaches of risk measurement

\begin{tabular}{lcc}
\hline & \multicolumn{2}{c}{ Predictive power of Model } \\
\cline { 2 - 3 } Segment & RMSE using Variance approach & $\begin{array}{c}\text { RMSE using Downside } \\
\text { Semi-Variance approach }\end{array}$ \\
\hline segment1 & 51.9562 & 46.6899 \\
segment2 & 58.0835 & 44.0031 \\
segment3 & 24.5164 & 75.2170 \\
segment4 & 83.1027 & 61.6487 \\
segment5 & 55.4322 & 10.8093 \\
segment6 & 26.0491 & 7.8497 \\
segment7 & 26.8906 & 30.8338 \\
segment8 & 6.5248 & 3.5935 \\
\hline Whole Portfolio & 134.5258 & 121.3114 \\
\hline
\end{tabular}

\section{References}

Berger, P. D., \& Nasr, N. I. (1998). Customer lifetime value: marketing models and applications. Journal of interactive marketing, 12(1), 17-30.

Buhl, H. U., \& Heinrich, B. (2008). Valuing customer portfolios under risk-return-aspects: a modelbased approach and its application in the financial services industry. Academy of Marketing Science Review, 12(5), 1-32. 
Dhar, R., \& Glazer, R. (2003). Hedging customers. Harvard Business Review,81(5), 86-92.

Dwyer, R. F. (1989). Customer lifetime valuation to support marketing decision making. Journal of direct marketing, 3(4), 8-15.

Estrada, J. (2002), Systematic risk in emerging markets: the D-CAPM, Emerging Markets Review, $365-379$.

Fader, P., Hardie, B., \& Berger, P. D. (2004). Customer-base analysis with discrete-time transaction data. Available at SSRN 596801.

Fader, P. S., Bruce, G. S., \& Ka, L. L. (2005). RFM and CLV: Using Iso-CLV curves for customer base analysis. Journal of Marketing Research, 42, 415-30.

Gruca, T. S., \& Rego, L. L. (2005). Customer satisfaction, cash flow, and shareholder value. Journal of Marketing, 69, 115-130.

Gupta, S., Lehmann, D., \& Ames Stuart, J. (2004). Valuing customers. Journal of marketing research, 7-18.

Gupta, S., Hanssens, D., Hardie, B., Kahn, W., Kumar, V., Lin, N., ... \& Sriram, S. (2006). Modeling customer lifetime value. Journal of Service Research, 9(2), 139-155.

Hogan, J. E., Lehmann, D. R., Merino, M., Srivastava, R. K., Thomas, J. S., \& Verhoef, P. C. (2002). Linking customer assets to financial performance. Journal of Service Research, 5(1), 26-38.

Hopkinson, G., \& Yu Lum, C. (2002). Valuing customer relationships: Using the capital asset pricing model (CAPM) to incorporate relationship risk. Journal of Targeting, Measurement and Analysis for Marketing, 10(3), 220-232.

Hughes, A. M. (1994). Strategic database marketing. Chicago: Probus publishing.

Jain, D., \& Singh, S. S. (2002). Customer lifetime value research in marketing: A review and future directions. Journal of interactive marketing, 16(2), 34-46.

Kundisch, D., Sackmann, S., \& Ruch, M. (2008). Transferring portfolio selection theory to customer portfolio management-The case of an e-tailer. In Enterprise Applications and Services in the Finance Industry (pp. 32-49). Springer Berlin Heidelberg.

Rego, L. L., Billett, M. T., \& Morgan, N. A. (2009). Consumer-based brand equity and firm risk. Journal of Marketing, 73(6), 47-60.

Reichheld, F. F. (1996), The Loyalty Effect. Boston: Harvard Business School Press.

Reinartz, W. J., \& Kumar, V. (2000). On the profitability of long-life customers in a noncontractual setting: An empirical investigation and implications for marketing. The Journal of Marketing, 17-35.

Rust, R. T., Lemon, K. N., \& Zeithaml, V. A. (2004). Return on marketing: using customer equity to focus marketing strategy. Journal of marketing, 109-127.

Ryals, L. (2003). Making customers pay: measuring and managing customer risk and returns. Journal of strategic marketing, 11(3), 165-175.

Ryals, L. J., \& Knox, S. (2005). Measuring risk-adjusted customer lifetime value and its impact on relationship marketing strategies and shareholder value. European Journal of Marketing, 39(5/6), 456-472.

Sackmann, S., Kundisch, D., \& Ruch, M. (2010). Customer portfolio management in e-commerce: an analytical model for optimization. Management Research Review, 33(6), 617-634.

Schmittlein, D. C., Morrison, D. G., \& Colombo, R. (1987). Counting Your Customers: Who-Are They and What Will They Do Next?. Management science, 33(1), 1-24.

Schmittlein, D. C., \& Peterson, R. A. (1994). Customer base analysis: An industrial purchase process application. Marketing Science, 13(1), 41-67.

Srivastava, R. K., Shervani, T. A., \& Fahey, L. (1998). Market-based assets and shareholder value: a framework for analysis. The Journal of Marketing, 62, 2-18.

Stahl, H. K., Matzler, K., \& Hinterhuber, H. H. (2003). Linking customer lifetime value with shareholder value. Industrial Marketing Management, 32(4), 267-279.

Tarasi, C. O., Bolton, R. N., Hutt, M. D., \& Walker, B. A. (2011). Balancing risk and return in a customer portfolio. Journal of Marketing, 75(3), 1-17.

Von Wangenheim, F., \& Lentz, P. (2005). Customer portfolio analysis: applying financial risk and volatility measures to customer segmentation and risk-adjusted lifetime value determination. Available at SSRN 782064. 